Immunolocalization of aquaporins 1,3 , and 5 in the nasal respiratory mucosa of a panting species, the sheep (Ovis aries)

Kristine Vesterdorf ${ }^{\mathrm{a}}$, Dominique Blache ${ }^{\mathrm{b}}$, and Shane K. Maloney ${ }^{\mathrm{a}}$ 5

${ }^{\mathrm{a}}$ School of Anatomy, Physiology and Human Biology M309, The University of Western Australia, 35 Stirling Highway, Crawley WA 6009, Australia

${ }^{\mathrm{b}}$ UWA Institute of Agriculture (Animal Production) M085, The University of Western

Australia, 35 Stirling Highway, Crawley WA 6009, Australia

10

Corresponding author:

20 Shane Maloney

School of Anatomy, Physiology and Human Biology M309

The University of Western Australia

35 Stirling Highway

Crawley WA 6009

25 Australia

Email: Shane.maloney@uwa.edu.au

Phone: +61 864883394

Fax: $\quad+61864881025$ 


\begin{abstract}
The nasal respiratory mucosa is the primary site for evaporative water loss in panting species, necessitating the movement of water across the nasal epithelium. Aquaporins (AQP) are protein channels that facilitate water movement in various fluid transporting tissues of non-panting species. Whether the requirement for enhanced capacity for transepithelial water movement in the nasal respiratory mucosa of panting species has led to differences in AQP localization is unknown. Using immunohistochemistry, we report the localization of AQP1, 3, and 5 in the nasal respiratory mucosa of sheep being exposed to ambient temperatures of $\sim 21^{\circ} \mathrm{C}$ or $\sim 38^{\circ} \mathrm{C}$ for 4.5 hours before death ( $n=3 /$ treatment). Exposure to either treatment resulted in panting. While

40 exposure to $\sim 38^{\circ} \mathrm{C}$ resulted in a higher respiratory frequency (mean difference: 82 breaths. $\mathrm{min}^{-1}$; $P<0.001$ ) than exposure to $\sim 21^{\circ} \mathrm{C}$, there was no difference in the localization of AQPs.

Connective tissue and vascular endothelial cells expressed AQP1. Glandular acini expressed AQP1 and apically localized AQP5, which was also present in glandular duct cells. Ciliated columnar epithelial cells expressed AQP5 apically and AQP3 basolaterally. Basal cells

expressed AQP3. The distribution and co-localization of AQPs in the ovine nasal respiratory mucosa is different to that reported in non-panting species and may reflect the physiological demands associated with enhanced respiratory evaporation. We propose that AQP1, 3, and 5 may constitute a transepithelial water pathway via glandular secretions and across the surface epithelium, which provides a possible means for rapid and controllable water movement in the nasal respiratory mucosa of a panting species.
\end{abstract}

\title{
60 Keywords
}

Mammals, water channel protein, water movement, thermoregulation, respiratory evaporative water loss, airway epithelia 


\section{Introduction}

65 In panting species, respiratory evaporative heat loss (REHL) is facilitated by coordinated changes in the flow of both air and blood across the respiratory epithelium. When the requirement for REHL increases there is an increase in respiratory frequency $\left(f_{\mathrm{R}}\right)$, which enhances the transfer of heat from the nasal mucosal surface to the air, and an increase in blood flow to the nasal mucosa, which increases heat delivery from the body to the nasal mucosal surface (Schroter and Watkins, 1989). Water exchange over the highly vascularized respiratory turbinates enhances heat loss by promoting evaporation in panting mammals (Hales, 1973), birds (Murrish, 1973), and reptiles (Tattersall et al., 2006). Heat and water added upon inspiration is lost to the environment upon expiration (Murrish, 1973). The nasal mucosal epithelium is the primary site for respiratory evaporative water loss (REWL) (Hales, 1973;

75 Murrish, 1973; Murrish and Schmidt-Nielsen, 1970), and the efficiency of REWL depends on the continuous replacement of water that is evaporated from the mucosal surface by water passaging from the blood to the respiratory surfaces (Cauna and Cauna, 1975). How that water reaches the surface epithelium is unknown. Blatt and coworkers (1972) concluded that two large glands present in the dog nasal epithelium, the lateral nasal glands, could account for only 19 to

$8036 \%$ of the water evaporated from the respiratory tract in panting dogs, leaving the majority of the water unaccounted for.

In most non-panting species water moves down an osmotic gradient from the vascular and cellular compartments to the respiratory mucosal epithelial surface (Man et al., 1979; Song et al., 2001), a mechanism that maintains the airway surface liquid (Nielsen et al., 1997; Song et al., 2001). Although most cell membranes are water permeable to some extent because of water diffusion through the lipid bilayer, some functions, including epithelial fluid secretion in the proximal tubule, salivary and lung submucosal glands, and in ciliary epithelia, require high transepithelial water permeability to meet physiological demands. Aquaporins (AQP) are 28

$90 \mathrm{kDa}$ transmembrane proteins that enhance such bidirectional water permeability facilitating high rates of fluid transport across cell membranes (Verkman, 2011). The osmotic water permeability of cell membranes expressing AQPs is 5-50-fold higher than in cell membranes without AQPs (Verkman and Mitra, 2000). To date, thirteen AQPs have been identified in mammalian epithelial and endothelial cells and are expressed either apically or basolaterally in cell membranes (Verkman, 2011). 
The physiological demands for maintenance of the airway surface liquid in the nasal mucosal epithelium of a panting animal will be different to non-panting animals, because REWL increases the demand for water re-supply to the respiratory surfaces of the nasal epithelium.

100 While regular water diffusion across the lipid bilayer yields a low and finite capacity for transepithelial water movement, the presence of AQPs allows for a high capacity for water movement, and the water permeability can be controlled (Verkman, 2011). The distribution and localization of AQPs in the nasal mucosal epithelium of panting species is, however, unknown. In tissues that are noted for dynamic and tightly controlled water movement, AQPs may be 105 rapidly trafficked from intracellular vesicles to the cell plasma membrane, enhancing water permeability when the demand for water movement is high (Fushimi et al., 1993; Nielsen et al., 1995, Agre et al., 1995). Trafficking of AQP1 occurred within $30 \mathrm{~s}$ in astrocytes and within five min in cardiac myocytes (Conner et al., 2012 and Page et al., 1998, respectively), while trafficking of AQP5 occurred within $10 \mathrm{~min}$ in rat parotid acini and within five min in human 110 sweat glands (Ishikawa et al., 2000 and Inoue et al., 2013, respectively) upon exposure to elevated levels of $\left[\mathrm{Ca}^{2+}\right]$. Trafficking of AQP2 in collecting duct cells occurred within 30 min of exposure to Angiotensin II (Li et al., 2011), while trafficking of AQP3 was induced within 60 min of exposure to epinephrine in Caco-2 cells (Yasui et al., 2008).

There is little or no overlap in the cellular distribution of the different AQPs in the respiratory 115 epithelia, suggesting that AQPs are functionally specialized in these tissues. AQP1 is expressed in connective tissue cells and vascular endothelial cells in the airway of rats (Ablimit et al., 2006; Nielsen et al., 1997) and humans (Seno et al., 2012). AQP2 is expressed in ciliated columnar epithelial cells and in glandular acini of human nasal mucosa (Seno et al., 2012). AQP3 is expressed in 1) basal and ciliated columnar epithelial cells in lung and nasal mucosal 120 epithelia of rodents (Ablimit et al., 2006; Nielsen et al., 1997) and in basal cells and basolaterally in ciliated columnar epithelial cells in nasal mucosal epithelia of humans (Kreda et al., 2001), 2) the glandular acini of lung and nasal mucosal epithelia in rats (Ablimit et al., 2006; Nielsen et al., 1997) and humans (Kreda et al., 2001; Seno et al., 2012), and 3) the basal and columnar epithelial cells of bronchus and bronchioli in sheep (Liu et al., 2003). AQP5 is present 125 in alveolar type I cells in lung of rats (Nielsen et al., 1997) and sheep (Liu et al., 2003), and in glandular acini in the nasal mucosal epithelium of rats (Ablimit et al., 2006; Nielsen et al., 1997) and humans (Kreda et al., 2001; Seno et al., 2012). In the human (Kreda et al., 2001; Matsui et al., 2000) and ovine lung (Liu et al., 2003) and in human nasal epithelium (Kreda et al., 2001; Seno et al., 2012) AQP5 is furthermore expressed apically in ciliated columnar epithelial cells. 
While the AQP distribution has been studied in ovine lung (Liu et al., 2003), to date no studies have been conducted on the possible localization of AQPs in the nasal respiratory mucosa of sheep, or indeed of any panting species. Sheep achieve heat loss at high ambient temperatures $\left(\mathrm{T}_{\mathrm{a}}\right)$ predominantly by panting through the nose (Hales, 1973; Vesterdorf et al., 2011). If water

135 movement to the mucosal surface of the nasal epithelia in panting animals evolved as an increased capacity of the system for fluid movement already present for maintenance of the airway surface liquid in other non-panting species, then AQPs are likely to be involved.

In the present study we set out to determine the localization of AQP1, 2, 3, and 5 in the nasal

140 respiratory mucosa of panting sheep, all of which are present in water transporting epithelia in other non-panting animals, using immunohistochemistry with antibodies specific to ovine AQPs. We hypothesize that the localization of AQPs in the nasal respiratory mucosa in sheep, a species that in hot conditions relies heavily on evaporative heat loss primarily via panting, will be different from that of non-panting species, and further that the localization of AQPs present

145 in the various cell types will change with the increased physiological demand for REWL as sheep switch from low to high intensity panting.

\section{Materials and methods}

\subsection{Animals}

150 Six adult Merino ewes (mean body mass $\pm \mathrm{SD} ; 52.7 \pm 4.5 \mathrm{~kg}$; wool thickness $\sim 40 \mathrm{~mm}$ ) were obtained in July (Southern hemisphere winter) from the sheep flock at the University Farm Allandale in Western Australia where they had been kept in an outdoor paddock. Climate conditions leading up to the collection of the sheep were as follows: maximum and minimum mean daily temperatures were $18.0^{\circ} \mathrm{C}$ and $7.7^{\circ} \mathrm{C}$, respectively, for June, and $18.6^{\circ} \mathrm{C}$ and $5.1^{\circ} \mathrm{C}$

155 for July, 2005 (Gingin Aero weather station, $\mathrm{N}^{\mathrm{o}} .9178,31.46^{\circ} \mathrm{S}, 115.86^{\circ} \mathrm{E}$, Bureau of Meteorology, Australia, www.bom.gov.au/jsp/ncc/cdio/weatherdata/). The sheep were transported to the Large Animal Facility at the University of Western Australia, Perth, where they were housed indoors in individual pens at the standard animal house $\mathrm{T}_{\mathrm{a}}$ of $\sim 21^{\circ} \mathrm{C}$ with lights on from 0600-1800h. The animals were provided with a maintenance diet of chaff,

160 lucerne, and lupin seed and water ad libitum. The sheep were familiarized with the experimental procedures for two weeks leading up to the experimental procedure. 
All procedures involving the animals were conducted in accordance with The Australian Code of Practice for the Care and Use of Animals for Scientific Purposes ( $7^{\text {th }}$ Edition, 2004) and approved by the UWA Animal Ethics Committee (Approval RA/3/100/280).

\subsection{Experimental procedures}

For the last 4.5 hours before death, starting at $10 \mathrm{am}$, three sheep continued to be exposed to a $\mathrm{T}_{\mathrm{a}}$ of $\sim 21^{\circ} \mathrm{C}$ and $44 \% \mathrm{RH}$. At the same time, the other three sheep were placed in a separate climate

170 chamber and exposed to a $\mathrm{T}_{\mathrm{a}}$ to $\sim 38^{\circ} \mathrm{C}$ and $26 \% \mathrm{RH}$ with an additional heat source from three $800 \mathrm{~W}$ infrared lamps placed $1 \mathrm{~m}$ above the sheep. A time frame of 4.5 hours of heat load exposure should allow the sheep to reach steady state of core body temperature by increasing respiratory frequency and elevating respiratory evaporative water loss (REWL) as found in a previous study by this group (40 min at similar heat load conditions; unpublished observation

175 from the experiments reported in Vesterdorf et al., 2010), and, given the latency period in other water transporting tissues, should allow any trafficking of AQPs to occur in the nasal respiratory tissues. Ambient temperature was measured in the two climate chambers using HOBO temperature dataloggers (HOBO Temp/Humidity Data Logger, Onset Computer Corp., Australia) and downloaded using Boxcar for Windows version 3.7.3 (Onset Computer Corp.,

180 Australia). Rectal temperature $\left(\mathrm{T}_{\text {rec }}\right)$ was measured by inserting a thermocouple, sheathed in polyvinylchloride tubing, $100 \mathrm{~mm}$ beyond the rectal sphincter. In the sheep exposed to $\sim 21^{\circ} \mathrm{C}$ the thermocouples were read using a handheld thermocouple reader (Omega Microprocessor Thermometer, HH21, Omega Engineering, USA), while in the sheep exposed to $\sim 38^{\circ} \mathrm{C}$ the thermocouples were logged every 5 s on a Datataker DT500 (Data Electronics, Australia, Pty.

185 Ltd.) and stored via DeTerminal (DeTerminal software, Data Electronics, Australia, Pty. Ltd.) on a personal computer. The thermocouples were calibrated in an insulated water bath against a certified mercury-in-glass thermometer. Respiratory frequency $\left(b \cdot \mathrm{min}^{-1}\right)$ was monitored visually for $5 \mathrm{~min}$ every $30 \mathrm{~min}$ for the last 4.5 hours before death and quantified using a tally counter.

\subsection{Tissue collection}

After the 4.5 hour exposure the sheep were killed for tissue collection. The sheep were injected intravenously with 25,000 i.u. of heparin (Amersham Pharmacia Biotech AB, Sweden) approximately $5 \mathrm{~min}$ prior to an intravenous overdose of Pentobarbitone Sodium (Lethabarb 165 mg.kg ${ }^{-1}$, Virbac Australia, Australia). The heads of the sheep were separated from the body and perfused, via the carotid arteries, with 2 litres of $0.9 \%$ saline followed by 3 litres of $4 \%$ 
paraformaldehyde in 0.1 M phosphate buffer ( $\mathrm{pH}$ 7.4) using an Easy-Load II pump (Masterflex $\mathrm{L}_{1} \mathrm{~S}^{\mathrm{TM}}$, Cole-Parmer Instrument Co., UK; flow rate $200 \mathrm{ml} \cdot \mathrm{min}^{-1}$ ).

The nasal bone was cut in a frontal plane at the level of the first molar using a handsaw. Deep coronal sections $(2 \mathrm{~cm})$ of the respiratory turbinates and the septum (Fig. 1) were separated by scalpel and removed. The different regions were identified based on observations by Negus (1958). Cross sections of the kidney that included both the cortex and medulla $(5 \mathrm{~cm} \times 5 \mathrm{~cm})$ and of the lung (mid-lobe region; $5 \mathrm{~cm}$ x $5 \mathrm{~cm}$ ) were also collected as control tissues. All tissue was immediately transferred for post fixing into $4 \%$ paraformaldehyde in $0.1 \mathrm{M}$ phosphate

205 buffer $(\mathrm{pH} 7.4)$ and stored at $4^{\circ} \mathrm{C}$ for three days.

\subsection{Tissue decalcification}

Nasal tissue is calcified and is thus difficult to section and also adheres poorly to slides. Therefore the tissue was decalcified prior to processing. All tissues were immersed in $10 \%$ 210 disodium-EDTA in $0.05 \mathrm{M}$ phosphate buffer (ten-fold solution to volume of tissue) for 72 hours, and then transferred to $0.05 \mathrm{M}$ phosphate buffer ( $\mathrm{pH}$ 7.4) for a further 72 hours. All tissues were placed in $70 \%$ ethanol and kept at $4^{\circ} \mathrm{C}$ until embedding. Paraffin embedding was performed at CellCentral at UWA, using an automated rotary tissue processor.

\section{$215 \quad 2.5$ Immunohistochemistry}

Coronal sections of tissue $(4 \mu \mathrm{m})$ were cut on a manual microtome (Shandon AS325 Retraction Microtome, Rankin Biomedical Corporation, USA) and mounted on positively charged slides (Esco Superfrost Plus, 25 x 75 x 1 mm, Biolab Scientific Ltd., Australia). Three tissue sections per animal per site were subjected to antigen retrieval prior to processing for immunohistochemistry. Specifically, sections were dewaxed in toluene, dehydrated in ethanol, rehydrated in double-distilled water, and finally placed in sodium citrate buffer ( $\mathrm{pH}$ 6.0) in a microwave (at $800 \mathrm{~W}$ ) twice for $4 \mathrm{~min}$.

The tissue sections were washed in Tris buffered solution (TBS; $\mathrm{pH} 7.4$ ) and placed in $3 \%$

$225 \mathrm{H}_{2} \mathrm{O}_{2} /$ methanol for 10 min to block endogenous peroxidase activity. To block non-specific antibody absorption the tissue sections were immersed in $0.08 \mathrm{M} \mathrm{NH}_{4} \mathrm{Cl}$ in TBS for $10 \mathrm{~min}$, washed twice in TBS, and incubated in 10\% normal pig serum in TBS for $30 \mathrm{~min}$. The tissue sections were incubated at $4^{\circ} \mathrm{C}$ for 24 hours with anti-AQP1 or 3 (Johnston et al., 2000), antiAQP2 (Butkus et al., 1999) or anti-AQP5 (Liu et al., 2003) antibody. Each anti-AQP antibody 
230 was raised in rabbit and affinity purified against a specific, small and unique region of the relevant AQP molecule that prevented cross-reactivity between the antibodies and other AQP proteins (Butkus et al., 1999; Johnston et al., 2000; Liu et al., 2003). The optimal working solutions, 1:3000 for AQP1 and AQP5, and 1:6000 for AQP2 and AQP3 (all diluted in buffer solution), were determined from a dilution series for each anti-AQP antibody in the relevant

235 positive control tissue (see below, section 2.6).

The sections were washed in TBS ( $3 \times 5 \mathrm{~min})$ prior to incubation with $2 \%$ normal sheep serum/secondary antibody (10 min). This step was included to absorb potential cross reactants with the secondary antibody's immunoglobulins. The sections were subsequently washed in

240 TBS (3 x 5 min) and immersed in conjugant streptavidin-horseradish complex (DAB LSAB+ system-HRP, 3,3'-diaminobenzidine [DAB] chromogen, streptavidin-horseradish peroxidase kit, DakoCytomation, USA) for $10 \mathrm{~min}$, then washed in TBS ( 3 x $5 \mathrm{~min}$ ). The sections were then incubated under silver foil with DAB chromogen (from the same kit mentioned above) for 5 min and subsequently washed in double-distilled water $(3 \times 5 \mathrm{~min})$ and counterstained under silver

245 foil for 1 minute using Lillie Mayer's Haematoxilin. The counterstain reaction was halted with acid ethanol. The tissue sections were washed, dehydrated with $70 \%$ followed by $100 \%$ ethanol, then toluene, and finally mounted and dried.

\subsection{Controls}

250 Positive and negative controls for each anti-AQP antibody were included in each batch of sections that were processed. Positive controls consisted of kidney tissue for AQP1 (Wintour et al., 1998), AQP2 (Butkus et al., 1999) and AQP3 (Liu et al., 2003), and lung tissue for AQP5 (Liu et al., 2003). Negative controls followed identical preparation with omission of the primary antibody. Further, the specificity of each primary antibody was tested after being incubated with 255 100-fold excess of its antigen peptide in TBS at $4^{\circ} \mathrm{C}$ overnight. The absorbed primary antibody was used on the appropriate control tissue following the method described above.

\subsection{Microphotographs}

Pictures of light microscopy (Olympus BH-2 microscope, with magnification Olympus D-Plan 260 objective lenses, Olympus America Inc., USA) views of the tissue sections were taken using a digital camera (Sony DFW-SX900, Sony Electronics Inc., USA) coupled with image analysis software (Unibrain Fire-i version 3.0, Unibrain Inc., USA) on a computer (NeXT PC, Next Computer Inc., USA). Evaluation of staining presence for each AQP in the various cell types 
was based on subjective estimates by all authors after microscope examination of several tissue sections.

\subsection{Statistical analysis}

All data are reported as mean \pm standard deviation unless otherwise stated. During the 4.5 hour temperature exposure, respiratory frequency was calculated based on averages of readings made at 30-min intervals $(n=9)$ and analyzed for $n=3$ sheep per treatment group. Rectal temperature was averaged for every $30 \min (n=9)$ and analyzed for $n=3$ sheep per treatment group. All data were analyzed using a one-way analysis of variance (one-way ANOVA, XLSTAT for Mac, Addinsoft SARL, US.) to determine the effect of $\mathrm{T}_{\mathrm{a}}$. The level of significance was set at $P<$ 0.05 .

\section{Results}

\subsection{Rectal temperature and respiratory frequency}

During the 4.5 hours exposure prior to death, the average $\mathrm{T}_{\text {rec }}$ in the sheep exposed to $\sim 38^{\circ} \mathrm{C}$ was higher than in the sheep exposed to $\sim 21^{\circ} \mathrm{C}\left(39.4 \pm 0.3^{\circ} \mathrm{C}\right.$ vs. $38.6 \pm 0.3^{\circ} \mathrm{C}$, respectively; $P<$

280 0.01). The $f_{\mathrm{R}}$ was on average $53 \pm 15 \mathrm{~b} \cdot \mathrm{min}^{-1}$ in the sheep exposed to $\sim 21^{\circ} \mathrm{C}$, indicating that the sheep were panting (Hales, 1973). Exposure to $\sim 38^{\circ} \mathrm{C}$ resulted in a higher $f_{\mathrm{R}}$ of $135 \pm 18 \mathrm{~b} \cdot \mathrm{min}^{-1}$ compared to that of sheep exposed to $\sim 21^{\circ} \mathrm{C}$ (mean difference: 82 breaths.min ${ }^{-1}$; $\mathrm{P}<0.001$ ) and the mode of respiration was rapid shallow panting, as described by Hales (1973).

\section{$285 \quad 3.2$ Localization of aquaporins}

Aquaporins were detected in paraffin sections of the respiratory mucosal epithelium taken from the respiratory turbinates and nasal septum of sheep (Fig. 1). Lung and kidney tissues were used as positive controls and negative controls using the antigen peptide for the appropriate AQP (Fig. 2). The anti-AQP antibodies detected AQP1, 2, 3, and 5 in the positive control tissues and

290 in the nasal mucosa. In all tissues the absorption of the primary antibody for AQP1, 3 and 5 with excess of the respective antigen peptides confirmed that the staining was specific. Staining for AQP2 was visible in the kidney and nasal sections of the negative controls, following absorption of the primary antibody with the AQP2 antigen peptide, indicating non-specific staining. Thus, while AQP2 staining was evident in the nasal mucosa, the data for AQP2 are considered

295 unreliable and are not presented in this study. 
The higher $f_{\mathrm{R}}$ in the sheep exposed to $\sim 38^{\circ} \mathrm{C}$ did not affect the intracellular localization of $\mathrm{AQP} 1,3$, or 5 in the different cell types compared to the sheep exposed to $\sim 21^{\circ} \mathrm{C}$. Furthermore, the two types of tissue from the nasal cavity, namely the respiratory turbinates and the septum, 300 showed similar staining properties for AQP1, 3, and 5 in the tissues from both groups. We will therefore not distinguish between ambient temperature exposure or between the respiratory turbinates and the septum in the following description of the localization of AQPs within the nasal respiratory mucosa.

305 AQP1 was present in connective tissue cells (Fig. 3A, B), vascular endothelial cells (Fig. 3A) and also in glandular acini (Fig. 3A). It was not possible to determine the membrane positioning of AQP1 within these cell types. AQP3 was present in the basolateral membrane of ciliated columnar epithelial cells and in the basal cells of the mucosal surface epithelium (Fig. 4A, B), however, it was not possible to determine the membrane positioning within the basal cells.

310 AQP5 was present in the apical membrane of ciliated columnar epithelial cells (Fig. 5A, B). AQP5 was detected primarily in the apical membrane, but was also found internalized in the cytoplasm, of glandular duct cells and glandular acini (Fig. 5A).

Co-localization of the different AQPs was observed in several histological structures. AQP1 and

3155 were present in glandular acini. AQP5 was present in the apical membrane of the ciliated columnar cells of the respiratory mucosal surface epithelium, whereas AQP3 was localized predominantly in the basolateral membrane of these cells (Fig. 6).

\section{Discussion}

320 This study is the first to show the immunolocalization of aquaporins, namely AQP1, 3, and 5, in the nasal respiratory mucosa of a panting species. The distribution of aquaporins in most of the cell types was similar to that observed in non-panting species, including rats and humans (Ablimit et al., 2006; Kreda et al., 2001; Nielsen et al., 1997; Seno et al., 2012), however, the unexpected presence of AQP1 in glandular acini, which has not been demonstrated in the nasal respiratory mucosa of non-panting species, may be indicative of a functional adaptation to the physiological demands placed on the nasal respiratory mucosa of a panting animal. Overall, the distribution and co-localization of AQPs in the ovine nasal respiratory mucosa suggest a plausible transepithelial water movement route from the blood to the mucosal surface (Fig. 6). 
330 Exposure to a $\mathrm{T}_{\mathrm{a}}$ of $\sim 38^{\circ} \mathrm{C}$ resulted in elevated rectal temperatures in our sheep. In both treatments the sheep were panting, albeit at a higher frequency at the higher $\mathrm{T}_{\mathrm{a}}$. Panting exerts a physiological demand for increased transepithelial water movement to meet increased REWL (Hales, 1973), which may involve processes similar to those required for maintenance of the airway surface liquid in non-panting animals, but with an increased capacity for water

335 movement. The localization of expressed AQPs in the nasal respiratory mucosa did, however, not change with a 2.5 -fold increase in $f_{\mathrm{R}}$ as our sheep were exposed to an increased heat load, despite an increased demand for transepithelial water movement to meet a calculated 2.5 -fold increase in REWL (based on data in Vesterdorf et al., 2011). It is possible that the presence of AQPs, demonstrated in the nasal respiratory mucosa of our animals, represents an up-regulated

340 presence of AQPs in the cell membrane in response to the demand for increased transepithelial water movement in already panting animals compared to non-panting animals. Our finding may then indicate that the capacity for high transepithelial water movement of the already present AQPs was not fully utilized in our sheep exposed to $\sim 21^{\circ} \mathrm{C}$ and was therefore sufficient to accommodate the increased physiological demand for transepithelial water movement in the 345 sheep exposed to $\sim 38^{\circ} \mathrm{C}$. In addition, other mechanisms, including the presence and regulation of alternative AQPs such as for example AQP4 (Verkman, 2011), may have been activated at the higher $\mathrm{T}_{\mathrm{a}}$ to facilitate the extra requirement for REWL.

In sheep, AQP1 was present in the connective tissue and vascular endothelial cells as has been 350 shown in the nasal respiratory mucosa of rats (Ablimit et al., 2006; Nielsen et al., 1997) and humans (Kreda et al., 2001; Seno et al., 2012). Specific to the sheep respiratory mucosa, AQP1 was also detected in glandular acini and may be a functional adaptation to panting. AQP1 is expressed in the myoepithelial cells that occupy the interstices in the basal regions of salivary gland acini and glandular duct cells in humans (Gresz et al., 2001). It is possible that AQP1 in 355 and around the glandular cells might play a protective role in the maintenance of the aqueous environment. Furthermore, AQP5 was clearly localized in the apical membrane of the glandular acini, similar to the nasal respiratory mucosa of rats (Ablimit et al., 2006; Nielsen et al., 1997) and humans (Kreda et al., 2001; Seno et al., 2012). A functional role for AQP5 was illustrated by a $~ 50 \%$ decrease in fluid secretion from nasal mucosal glands in AQP5-null mice (Song and

360 Verkman, 2001). The presence of AQP1 and 5 in glandular cells could provide a transcellular pathway for water, with AQP5 in the apex allowing for the exit of water from the glandular cells into the gland lumen (Fig. 6), thus providing a passageway for water flow driven by the osmotic 
gradient created when increased REWL during panting creates an increase in the tonicity of the airway surface liquid.

365

AQP5 was also detected in the apical membrane of the ciliated columnar epithelial cells as was shown previously in the nasal respiratory mucosa of human (Kreda et al., 2001; Seno et al., 2012), but not rat (Ablimit et al., 2006; Nielsen et al., 1997). AQP5 could facilitate water transport in the surface of the ovine nasal respiratory mucosa, indeed, inhibition of AQP5 by 370 mercury decreased the water permeability in human airway surface epithelial cells (Matsui et al., 2000). However, the decrease in cell permeability was only partial $(\sim 30 \%)$, indicating that additional facilitators for water movement must be present (Matsui et al., 2000). The presence of AQP3 in the basal cells and in the basolateral membrane of ciliated columnar epithelial cells in sheep has also been reported in human (Kreda et al., 2001) and rat airway epithelia (Ablimit et 375 al., 2006; Matsuzaki et al., 1999; Nielsen et al., 1997). AQP3 plays a major role in protection of the skin against dehydration because as an aquaglyceroporin it facilitates the transfer of not only water but also glycerol across the cell membrane (Hara et al., 2002; Hara and Verkman, 2003; Matsuzaki et al., 1999).

380 Increased water loss from the mucosal surface results in hypertonic airway surface liquid, which increases the osmotically driven transepithelial water movement to the surface epithelium (Man et al., 1979). Hyperosmotic stress in human airway epithelia activated the rapid trafficking of AQP5 from cytoplasmic vesicles to the apical membrane (Pedersen et al., 2007), a physiological response, which has also been demonstrated in other tissues that have a variable demand for 385 water movement, including lung epithelial cells and parotid glands (Agre et al., 1995; Fushimi et al., 1993). The demonstrated presence of AQP5 in the ovine nasal mucosa might provide flexibility for the rapidly increasing transepithelial water movement that is necessary when REWL is stimulated in panting species. Further, the presence of AQP5 in not only ciliated columnar epithelial cells but also in glandular duct cells and the co-localization with AQP1 in 390 glandular acini and with AQP3 in ciliated columnar epithelial cells in the nasal respiratory mucosa of sheep could be part of the adaptation to panting.

Like AQP5, AQP2 is dynamically controlled between cytoplasmic vesicles and the cell membrane in the rat kidney collecting tubule (Fushimi et al., 1993; Nielsen et al., 1995). We suggest that the use of more sensitive molecular markers such as immunoflourescent dye (Bouley et al., 2011) or immunogold labelling (Xie et al., 2010), which have successfully 
detected AQP2 in kidney, might provide viable alternatives to detect AQP2 in the nasal mucosa of a panting species.

400 The distribution of aquaporins in the nasal respiratory mucosa of sheep suggests the existence of two pathways for water movement involving several cell types once water has crossed the blood vessel wall barrier into the connective tissue via AQP1 (Fig. 6). First, water could move across the glandular acini via AQP1 and AQP5 to form part of the glandular mucosal discharge, which is driven by an osmotic gradient (Walcott, 1998). Second, as water evaporates from the airway

405 surface liquid on the mucosal epithelial surface the tonicity of the airway surface liquid increases, creating the osmotic gradient necessary for water movement from the interstitium to the surface (Man et al., 1979). Water movement from the interstitium to the nasal epithelial surface in sheep may be facilitated by the localization AQP3 in basal cells and also in the basolateral membrane of the ciliated columnar epithelial cells where AQP5 is present apically.

410 These two pathways, via glandular secretions and across the surface epithelium, provide a possible means for the rapid control of water movement in the nasal respiratory mucosa of a panting species. Passive water movement, which underlies the above scenario, requires an osmotic gradient. In dogs, another species that pants under heat load, the fluid lining of the nasal respiratory mucosa is hypertonic to the interstitium (Man et al., 1979), evidence that passive

415 water movement from the interstitium to the mucosal surface could occur. It is unknown whether the aqueous surface of the nasal mucosa in panting sheep is hypertonic. If it is, then the above scenario would be supported, and the AQP distribution would facilitate the process. If it is not, then active secretion must be involved.

420 In summary, we show that the AQPs detected in the nasal respiratory mucosa of the sheep are appropriately localized to allow rapid transepithelial water movement in a panting species. The localization of AQP1 in vascular endothelial and connective tissue cells provides a water movement route across the blood vessel barrier to the nasal submucosal epithelium.

Furthermore, the detected AQP1 and apically localized AQP5 in glandular acini, and the 425 basolaterally localized AQP3 and apically localized AQP5 in ciliated columnar cells of the surface epithelium provide likely pathways for transepithelial water movement to the surface of the nasal respiratory mucosa of the sheep. Although the demand for transepithelial water movement in the nasal respiratory mucosa increased at higher $\mathrm{T}_{\mathrm{a}}$ due to an increase in REWL, the increased demand for water movement was not reflected in a change in the expression of 430 AQPs detected in the present study. We suggest that the presence of cell membrane and 
cytoplasmic vesicle-bound AQP5, an AQP that can be rapidly translocated to the membrane in response to increased physiological demands for rapid transepithelial water movement, and the presence of AQP1 in glandular acini, together may provide an added capacity for enhanced transepithelial water movement in panting animals when the demand arises. 


\section{Acknowledgements}

The study was supported by an Australian Research Council Discovery Project Grant

440 (DP0345058) to SKM and DB. Aquaporin antibodies were kindly supplied by E. Marelyn Wintour of Monash University, Victoria, Australia. The authors would like to thank the animal technicians at the Large Animal Facility at UWA for excellent animal care, Irek Malecki and Peter McFawn for use of microscopy facilities, and Alan Light, Margaret Blackberry, Mary Lee, Kristin Hunt, and Albert Roenning-Andersson for technical assistance. 


\section{References}

Ablimit, A., Matsuzaki, T., Tajika, Y., Aoki, T., Hagiwara, H., Takata, K., 2006. Immunolocalization of water channel aquaporins in the nasal olfactory mucosa. Arch. Histol. Cytol. 69, 1-12.

Agre, P., Brown, D., Nielsen, S., 1995. Aquaporin water channels: unanswered questions and unresolved controversies. Curr. Opin. Cell. Biol. 7, 472-483.

Blatt, C.M., Taylor, C.R., Habal, M.B., 1972. Thermal panting in dog. The lateral nasal gland, a source of water for evaporative cooling. Science. 177, 804-805.

Bouley, R., Lu, H.A.J., Nunes, P., Da Silva, N., McLaughlin, M., Chen, Y., Brown, D., 2011. Calcitonin has a vasopressin-like effect on aquaporin-2 trafficking and urinary concentration. J. Am. Soc. Nephrol. 22, 59-72.

Butkus, A., Earnest, L., Jeyaseelan, K., Moritz, K., Johnston, H., Tenis, N., Wintour, E.M., 1999. Ovine aquaporin-2: cDNA cloning, ontogeny and control of renal gene expression. Pediatr. Nephrol. 13, 379-390.

Cauna, N., Cauna, D., 1975. The fine structure and innervation of the cushion veins of the human nasal respiratory mucosa. Anat. Rec. 181, 1-16.

Conner, M. T., Conner, A. C., Bland, C. E., Taylor, L. H. J., Brown, J. E. P., Rheinallt Parri, H., Bill, R. M, 2012. Rapid aquaporin translocation regulates cellular water flow: mechanism of hypotonicity-induced subcellular localization of aquaporin 1 water channel. J. Biol. Chem. 287, 11516-11525.

Fushimi, K., Shinichi, U., Hara, Y., Hiratya, Y., Marumo, F., Sasaki, S., 1993. Cloning and expression of apical membrane water channel of rat kidney collecting tubule. Nature. 361, $549-52$.

Gresz, V., Kwon, T.H., Hurley, P.T., Varga, G., Zelles, T., Nielsen, S., Case, R.M., Steward, M.C., 2001. Identification and localization of aquaporin water channels in human salivary glands. Am. J. Physiol. Gastrointest. Liver. Physiol. 281, 247-254.

Inoue, R., Sohara, E., Rai, T., Satoh, T., Yokozeki, H., Sasaki, S., Uchida, S., 2013. Immunolocalization and translocation of aquaporin-5 water channel in sweat glands. J. Derm. Sci. 70, 26-33.

Ishikawa, Y., Skowronski, M. T., Ishida, H., 2000. Persistent increase in the amount of AQP 5 in the apical plasma membrane of rat parotid acinar cells induced by a muscarinic agonist SNI-2011. FEBS letters. 477, 253-257. 
480 Hales, J.R.S., 1973. Effects of exposure to hot environments on the regional distribution of blood flow and on cardiorespiratory function in sheep. Pflugers. Arch. 344, 133-148.

Hara, M., Ma, T., Verkman, A.S., 2002. Selectively reduced glycerol in skin of aquaporin-3deficient mice may account for impaired skin hydration, elasticity, and barrier recovery. J. Biol. Chem. 277, 46616-46621.

485 Hara, M., Verkman, A.S., 2003. Glycerol replacement corrects defective skin hydration, elasticity, and barrier function in aquaporin-3-deficient mice. Proc. Natl. Acad. Sci. USA. 100, 7360-7365.

Johnston, H., Koukoulas, I., Jeyaseelan, K., Armugam, A., Earnest, L., Baird, R., Dawson, N., Ferraro, T., Wintour, E.M., 2000. Ontogeny of aquaporins 1 and 3 in ovine placenta and fetal membranes. Placenta. 21, 88-99.

Kreda, S.M., Gynn, M.C., Fenstermacher, D.A., Boucher, R.C., Gabriel, S.E., 2001. Expression and localization of epithelial aquaporins in the adult human lung. Am. J. Respir. Cell. Mol. Biol. 24, 24-234.

Li, C., Wang, W., Rivard, C. J., Lanaspa, M. A., Summer, S., Schrier, R. W., 2011. Molecular 495 mechanisms of angiotensin II stimulation on aquaporin-2 expression and trafficking. Am. J. Physiol. Renal. Physiol. 300, F1255-F1261.

Liu, H., Hooper, S.B., Armugam, A., Dawson, N., Ferraro, T., Jeyaseelan, K., Thiel, A., Koukoulas, I., Wintour, E.M., 2003. Aquaporin gene expression and regulation in the ovine fetal lung. J. Physiol. 551, 503-514.

500 Man, S.F.P., Adams III, G.K., Proctor, D.F., 1979. Effects of temperature, relative humidity, and mode of breathing on canine airway secretions. J. Appl. Physiol. 46, 205-210.

Matsui, H., Davis, C.W., Tarran, R., Boucher, R.C., 2000. Osmotic water permeabilities of cultured, well-differentiated normal and cystic fibrosis airway epithelia. J. Clin. Invest. $105,1419-1427$.

505 Matsuzaki, T., Suzuki, T., Koyama, H., Tanaka, S., Takata, K., 1999. Water channel protein AQP3 is present in epithelia exposed to the environment of possible water loss. J. Histochem. Cytochem. 47, 1275-1286.

Murrish, D.E., 1973. Respiratory heat and water exchange in penguins. Resp. Physiol. 19, 262270.

510 Murrish, D.E., Schmidt-Nielsen, K., 1970. Exhaled air temperature and water conservation in lizards. Resp. Physiol. 10, 151-158.

Negus, V., 1958. Comparative anatomy and physiology of the nose and paranasal sinuses. F and S Livingstone Ltd., Edinburgh. 
Nielsen, S., Chou, C., Marples, D., Christensen, E.I., Kishore, B.K., Knepper, M.A., 1995. Vasopressin increases water permeability of kidney collecting duct by inducing translocation of aquaporins-CD water channels to plasma membrane. Proc. Natl. Acad. Sci. USA. 92, 1013-1017.

Nielsen, S., King, L.S., Christensen, B.M., Agre, P., 1997. Aquaporins in complex tissues. II. Subcellular distribution in respiratory and glandular tissues of rat. Am. J. Physiol. Cell. Physiol. 273, 1549-1561.

Page, E., Winterfield, J., Goings, G., Bastawrous, A., Upshaw-Earley, J., Doyle, D., 1998. Water channel proteins in rat cardiac myocyte caveolae: osmolarity-dependent reversible internalization. Am. J. Physiol. 274, H1998-H2000.

Pedersen, P.S., Braunstein, T.H., Jørgensen, A., Larsen, P.L., Holstein-Rathlou, N.H., Frederiksen, O., 2007. Stimulation of aquaporin-5 and transepithelial water permeability in human airway epithelium by hyperosmotic stress. Pflugers. Arch. 453, 777-785.

Seno, S., Ogawa, T., Shibayama, M., Kouzaki, H., Shimizu, T., 2012. Expression and localization of aquaporin 1, 2, 3, 4, and 5 in human nasal mucosa. Am. J. Rhinol. Allergy. $3,167-171$.

530 Schroter, R.C., Watkins, N.V., 1989. Respiratory heat exchange in mammals. Respir. Physiol. 78, 357-367.

Song, Y., Jayaraman, S., Yang, B., Matthay, M.A., Verkman, A.S., 2001. Role of aquaporin water channels in airway fluid transport, humidification, and surface liquid hydration. J. Gen. Physiol. 117, 573-582.

535 Song, Y., Verkman, A.S., 2001. Aquaporin-5 dependent fluid secretion in airway submucosal glands. J. Biol. Chem. 276, 41288-41292.

Tattersall, G.J., Cadena, V., Skinner, M.C., 2006. Respiratory cooling and thermoregulatory coupling in reptiles. Respir. Physiol. Neurobiol. 154, 302-318.

Verkman, A.S., 2011. Aquaporins at a glance. J. Cell. Sci. 124, 2107-2112.

540 Verkman, A.S., Mitra, A.K., 2000. Structure and function of aquaporin water channels. Am. J. Physiol. Renal. Physiol. 278, F13-F28.

Vesterdorf, K., Blache, D., Maloney, S.K., 2011. The cranial arterio-venous temperature difference is related to respiratory evaporative heat loss in a panting species, the sheep (Ovis aries). J. Comp. Physiol. B. 181, 277-288.

545 Walcott, B., 1998. The lacrimal gland and its veil of tears. News. Physiol. Sci. 13, 97-103. 
Wintour, E.M., Earnest, L., Alcorn, D., Butkus, A., Shandley, L., Jeyaseelan, K., 1998. Ovine AQP1: cDNA cloning, ontogeny, and control of renal gene expression. Pediatr. Nephrol. $12,545-553$.

Xie, L., Hoffert, J.D., Chou, C.L., Yu, M.J., Pisitkun, T., 2010. Quantitative analysis of aquaporin-2 phosphorylation. Am. J. Physiol. Renal. Physiol. 298, F1018-F1023.

Yasui, H., Kubota, M., Iguchi, K., Usui, S., Kiho, T., Hirano, K., 2008. Membrane trafficking of aquaporin 3 induced by epinephrine. Biochem. Biophys. Res. Comm. 373, 613-617. 


\section{Figure captions}

Fig. 1 Frontal cross-section of the nasal cavity of sheep at the first molar. Respiratory turbinates (A) Septum (B).

560 Fig. 2 Photomicrograph of immunohistochemical localization of aquaporins (AQPs) in positive control tissues. The nuclei were counterstained with haematoxylin (blue). The brown stain indicates the presence of AQP in the cytoplasm or cell membrane. When AQP labelling was performed in the presence of the corresponding antigen peptide, no positive labelling of that AQP was detected (negative control). AQP1 is present in the renal tubular cells, T (A). Negative control with peptide absorption of anti-AQP1 antibody (B). AQP3 is present in the basolateral membrane of collecting duct cells, CD (C). Negative control with peptide absorption of antiAQP3 antibody (D). AQP5 is present in the apical membrane of alveolar Type I epithelial cells, $\mathrm{Al}$ (E). Negative control with peptide absorption of anti-AQP5 antibody (F). Arrows indicate the presence of AQP.

Fig. 3 Photomicrograph of a section of nasal respiratory mucosa of sheep stained with antiAQP1 antibody and counterstained with haematoxylin. The brown stain indicates the presence of AQP in the cell membrane. The blue haematoxylin stain is present in cell nuclei. Arrows indicate the presence of AQP1. Abbreviations in photos: CT: connective tissue, G: mucous

575 gland, VEn: vascular endothelial cells. AQP1 was present in connective tissue (A, B), glandular acini (A), and vascular endothelial cells (A). Slides labeled with the corresponding antigen peptide showed no positive labelling of AQP1 (C).

Fig. 4 Photomicrograph of a section of nasal respiratory mucosa of sheep stained with anti580 AQP3 antibody and counterstained with haematoxylin. The brown stain indicates the presence of AQP3 in the cell membrane. The blue haematoxylin stain is present in cell nuclei. Arrows indicate the presence of AQP3. Abbreviations in photos: BC: Basal cells, CCE: ciliated columnar epithelial cells. AQP3 was present in the basolateral membrane of ciliated columnar epithelial cells, and in basal cells of the mucosal surface epithelium (A, B). Slides labeled with

585 the corresponding antigen peptide showed no positive labelling of AQP3 (C).

Fig. 5 Photomicrograph of a section of nasal respiratory mucosa of sheep stained with antiAQP5 antibody and counterstained with haematoxylin. The brown stain indicates the presence 
of AQP5 in the cytoplasm or cell membrane. The blue haematoxylin stain is present in cell

590 nuclei. Arrows indicate the presence of AQP5. Abbreviations in photos: CCE: ciliated columnar epithelial cells, G: mucous gland, GD: glandular duct. AQP5 was present apically in ciliated columnar epithelial cells (A, B), glandular acini (A), and in glandular duct cells (A). Slides labeled with the corresponding antigen peptide showed no positive labelling of AQP5 (C).

595 Fig. 6 Schematic diagram representing the distribution of AQP1, 3, and 5 in sheep nasal respiratory mucosa. Arrows represent possible water movement from capillaries to the nasal respiratory mucosal surface.

600

605

610 


\section{Vitae}

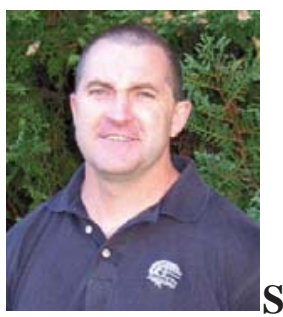

Shane Maloney is professor in the School of Anatomy, Physiology and Human

625 Biology at The University of Western Australia. His field of research is comparative physiology and his objective is to identify and explore the physiological mechanisms used by mammals and birds to adapt to environmental stressors. His primary focus is thermal physiology, particularly the regulation of brain temperature and the consequences of strategies used by animals to maintain thermal homeostasis. Shane collaborates with researchers from a broad range of 630 international universities and research centres in diverse areas, recently including giraffe hemodynamics, alpaca nutrition and thermoregulation, and animal ethics and welfare.

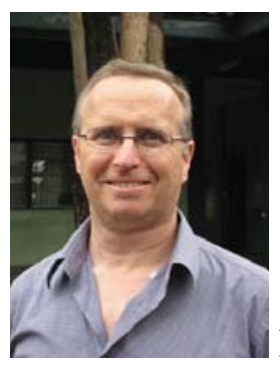

Dominique Blache is Associate Professor at the Institute of Agriculture (Animal Production) at University of Western Australia. His field of research is in reproductive

635 function, focussing on neural and hormonal pathways that regulate intake, body weight, and metabolism. Key research areas include the effects of nutrition on the ovine reproductive system; alpaca nutrition, reproduction, and fleece quality; animal ethics and welfare; understanding the motivation of producers to adopt new strategies to improve animal welfare. Working with sheep, emu and alpaca, Dominique uses a wide range of approaches, such as 640 behaviour, immunohistochemistry, and radioimmunoassay, to investigate these questions in collaboration with a wide international range of universities and research centres. 


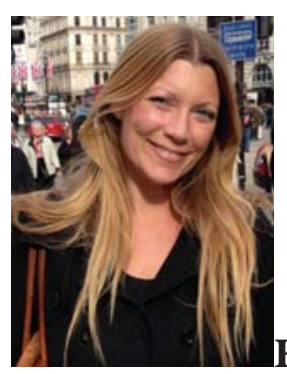

Kristine Vesterdorf is a young researcher who carried out her Master's degree in the field of thermoregulation, focussing on respiratory evaporative heat loss in sheep, at The

645 University of Western Australia. After obtaining her PhD degree in the field of reproduction, nutrition, and fetal metabolic programming of mink at University of Copenhagen, Denmark, in collaboration with University of Algarve, Portugal, Kristine now continues her work in the field of thermoregulation in Shane Maloney's lab, with the objective to identify the effects of external stressors on thermoregulatory mechanisms. 


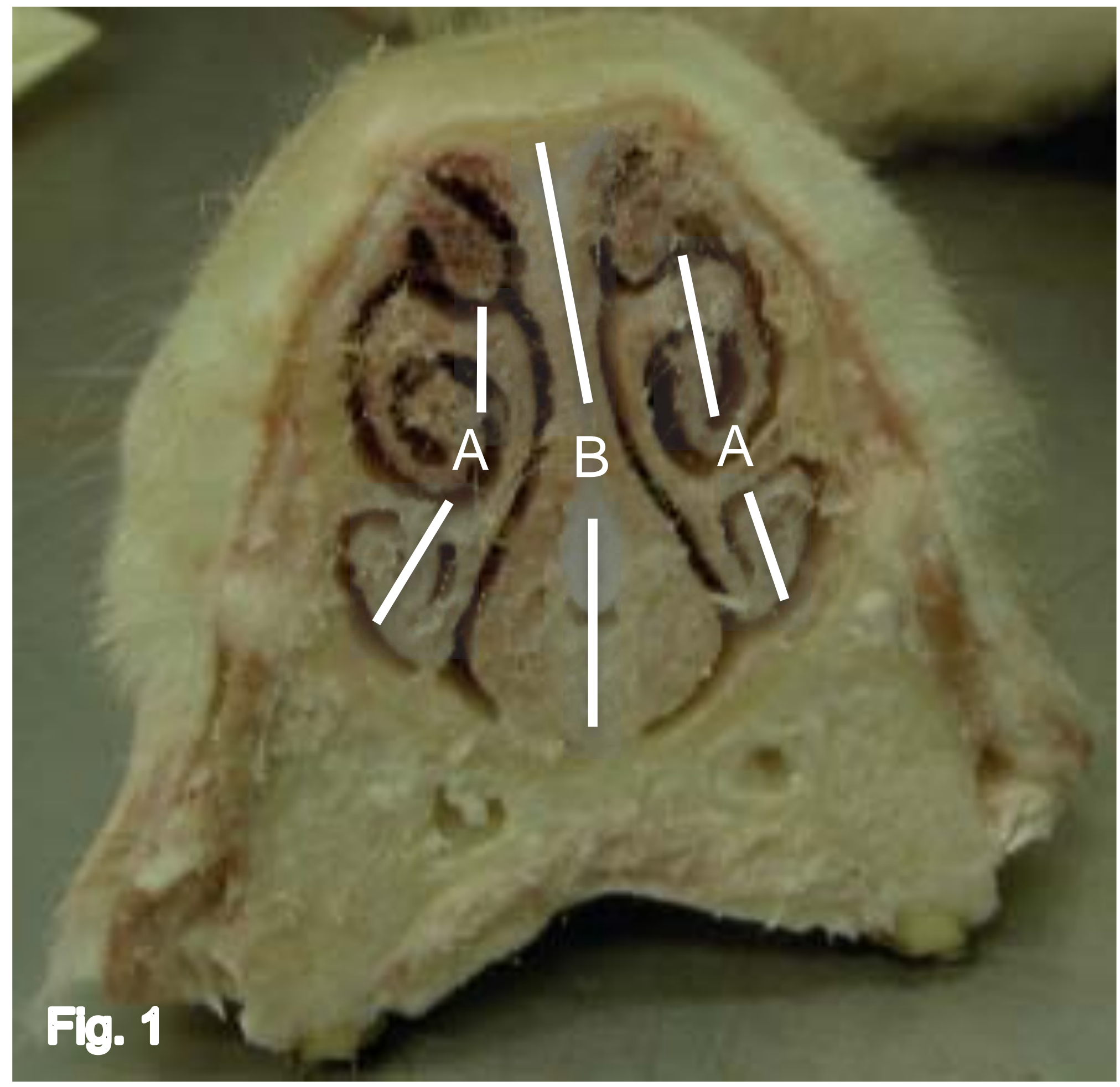


A.

B.

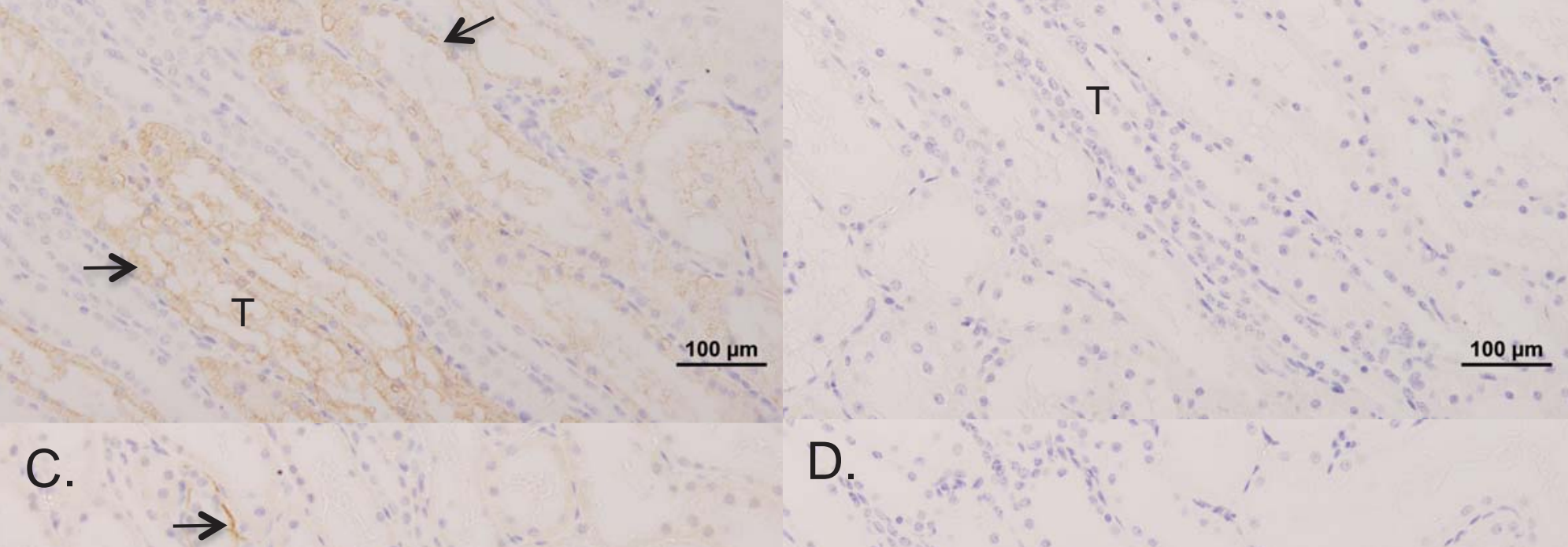

E.

$100 \mu \mathrm{m}$

$100 \mu \mathrm{m}$

Fig. 2

\section{A1}

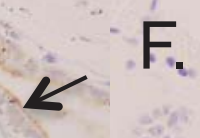




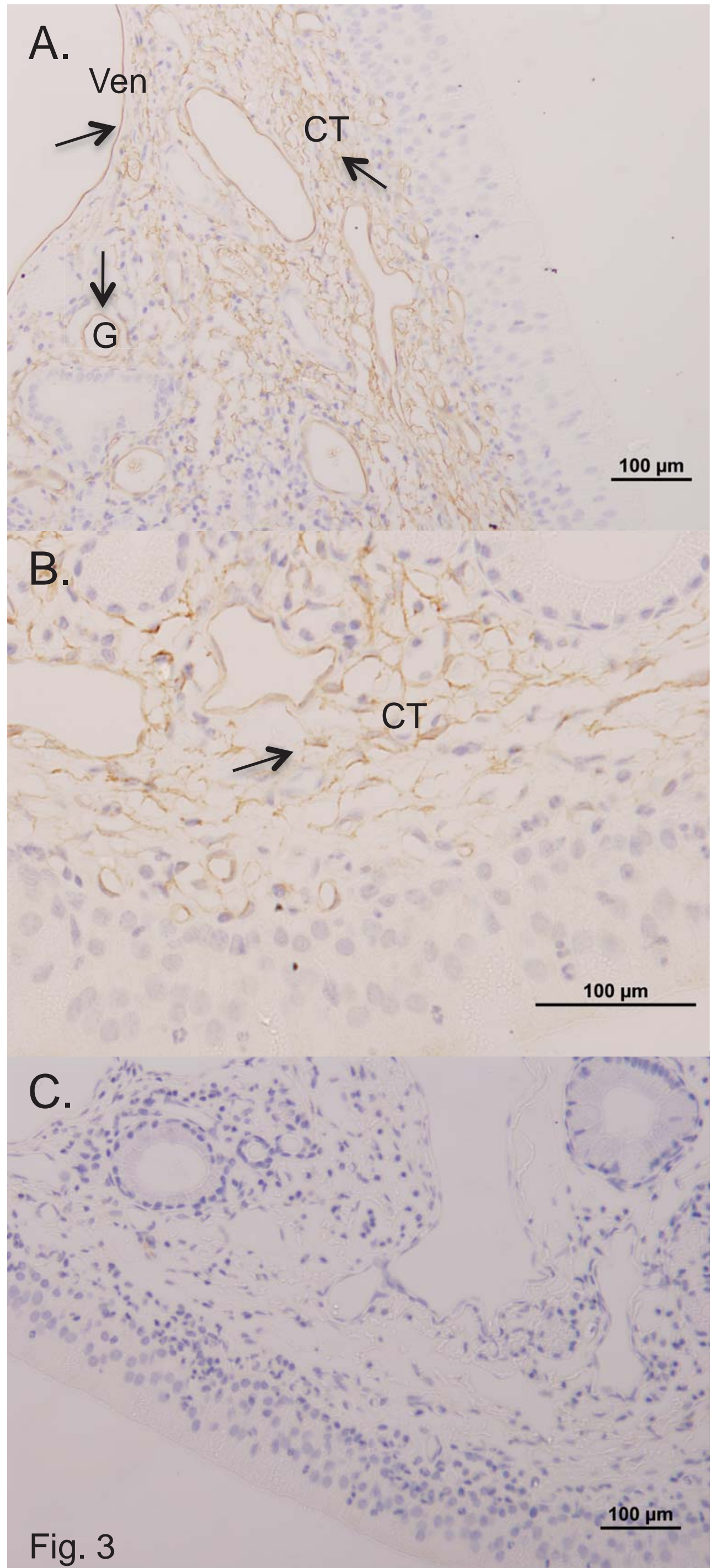




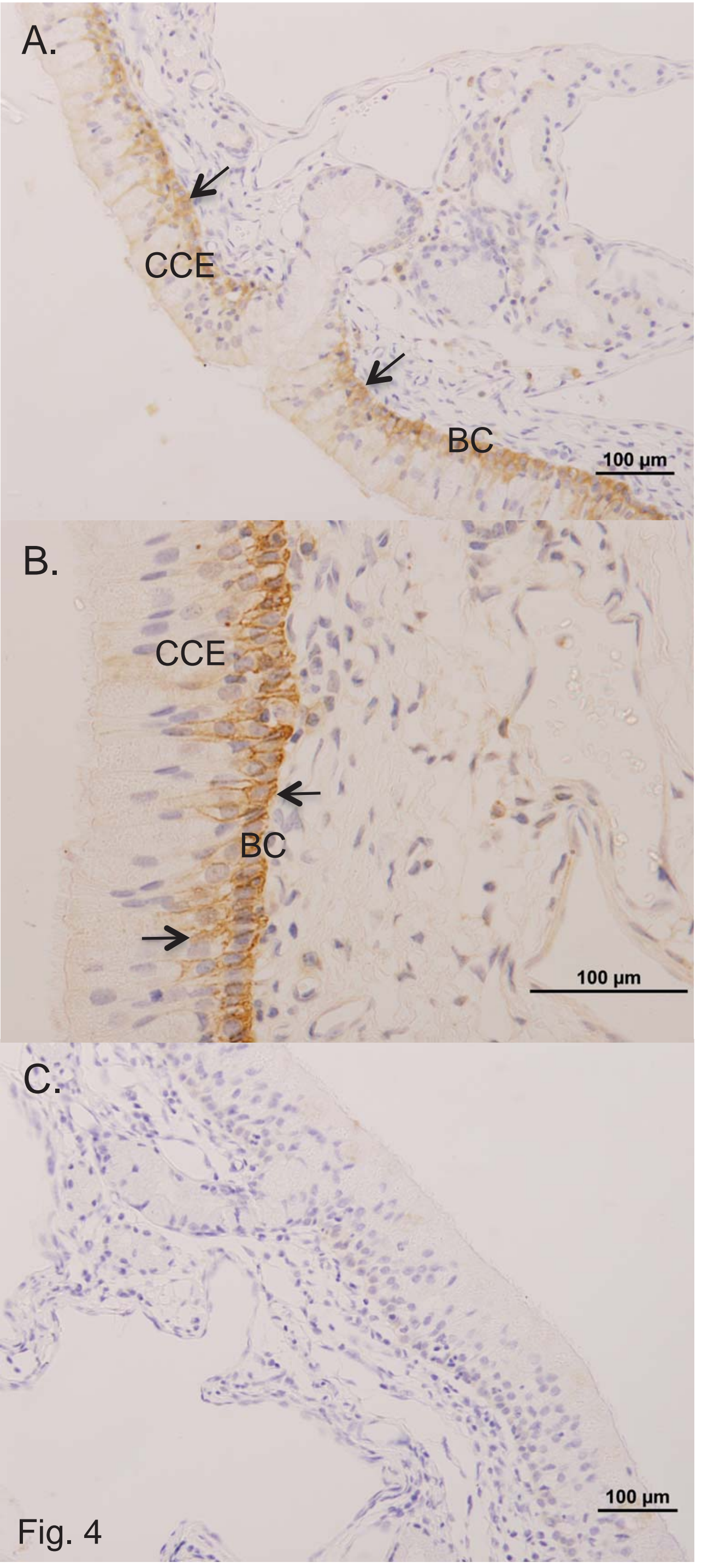




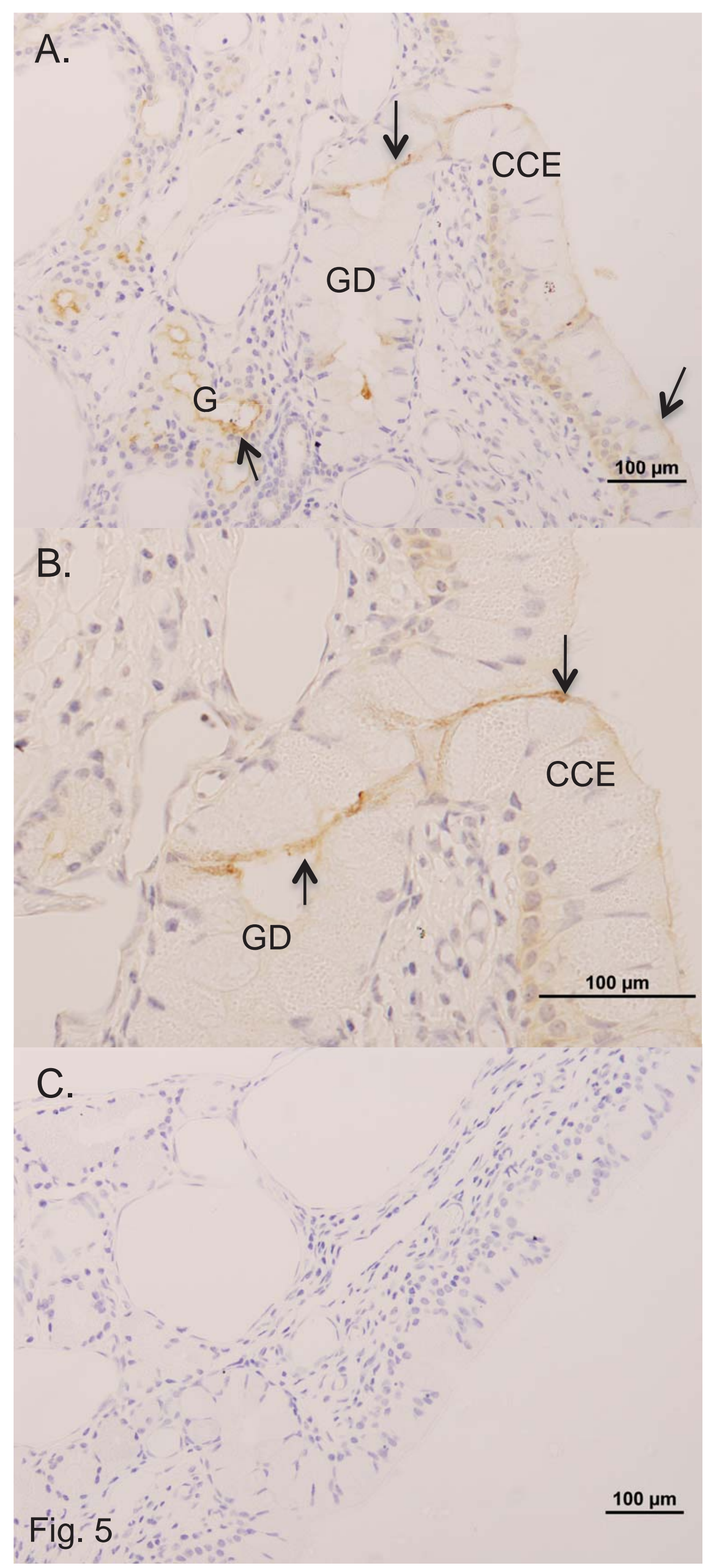




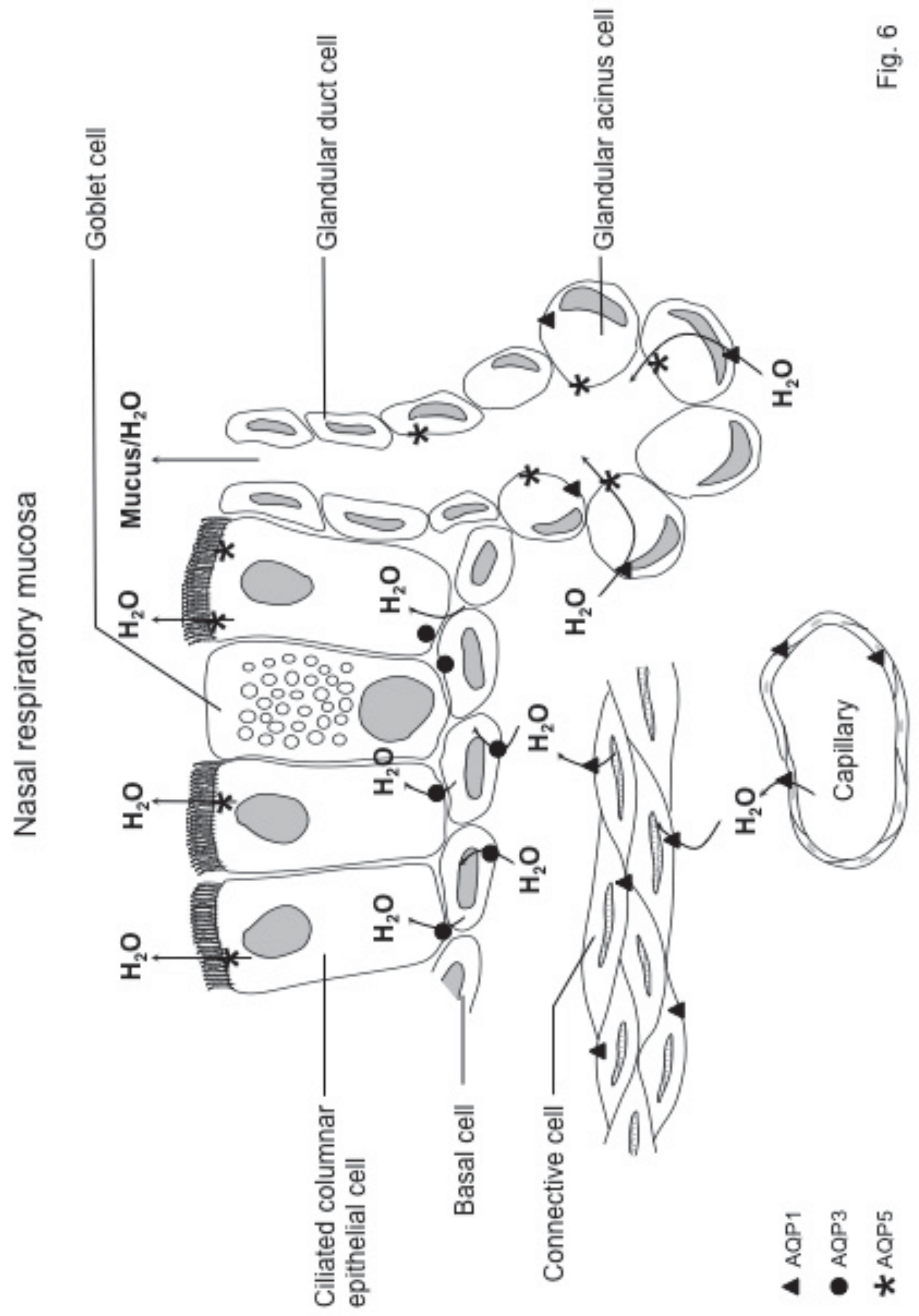

